\title{
A Miniaturized Triple Band Monopole Antenna for WLAN and WiMAX Applications
}

\author{
Yingsong $\mathrm{Li}^{1}$ and Wenhua $\mathrm{Yu}^{2}$ \\ ${ }^{1}$ College of Information and Communications Engineering, Harbin Engineering University, Harbin 150001, China \\ ${ }^{2} 2 \mathrm{COMU}$, Inc., 4031 University Drive, Suite 100, Fairfax, VA 22030, USA \\ Correspondence should be addressed to Yingsong Li; liyingsong@ieee.org
}

Received 4 February 2015; Accepted 15 April 2015

Academic Editor: Atsushi Mase

Copyright (c) $2015 \mathrm{Y}$. Li and W. Yu. This is an open access article distributed under the Creative Commons Attribution License, which permits unrestricted use, distribution, and reproduction in any medium, provided the original work is properly cited.

\begin{abstract}
A miniaturized triple band monopole antenna with a small size is proposed and its performance is investigated both numerically and experimentally for worldwide interoperability for microwave access (WiMAX) and wireless local area network (WLAN) applications. The three resonance frequencies are realized by using a toothbrush-shaped patch (TSP), a meander line (ML), and an inverted U-shaped patch (IUSP). The center frequencies of the triple bands can be controlled by adjusting the dimensions of the TSP, ML, and IUSP. Simulated and measured results are presented to demonstrate that the proposed triband monopole antenna with a good impedance bandwidth and omnidirectional radiation patterns is well suitable for WLAN and WiMAX communication applications.
\end{abstract}

\section{Introduction}

With the development of the wireless techniques, the demand for low profile, light weight, ease of implementation, and low cost broadband antennas is attractive for short distance communication devices $[1,2]$. Worldwide interoperability for microwave access (WiMAX) and wireless local area network (WLAN) are very popular wireless communication systems and have been widely studied and applied in mobile devices in recent years [1-4]. To improve the performance and make the antenna functional in a complicated and diverse WLAN and WiMAX environment, the antennas should cover multiple frequency bands and can provide stable omnidirectional radiation patterns and gains to render it suitable for WLAN (2.4$2.484,5.15-5.35$, and $5.725-5.825 \mathrm{GHz}$ ) and WiMAX (3.33.69 and $5.25-5.85 \mathrm{GHz}$ ) communication systems. Moreover, WLAN and WiMAX may be used simultaneously in the same system. Thus, it is necessary to design a single antenna to cover multiple bands. Several planar printed monopole antennas using slot structures and toothbrush patch have been proposed and well designed to achieve a wide-band property or a dual-band function for meeting wide-band communication applications [5-8]. However, some of these antennas cannot meet the ever-increasing multiple band communication requirements. In order to serve more communication systems, several multiband monopole antennas with meander lines have been presented in [9-12]. However, some of these reported multiband antennas cannot be integrated into portable devices as an internal antenna owing to their large sizes or complex structures. In addition, microstrip fed monopole antennas have been widely studied and applied to modern portable terminals owing to their simple structures and ease of fabrication and debugging [10, 13]. However, most of these monopole antennas are large in size.

In this paper, we propose a compact triband monopole antenna for WLAN and WiMAX operations. By using a toothbrush-shaped patch (TSP), a meander line (ML), and an inverted U-shaped patch (IUSP), three resonance frequencies can be obtained to operate at 2.4/3.5/5.2/5.5/5.8 GHz bands. The parameter effects on the impedance bandwidth are investigated by using the HFSS. Simulated and measured results show that the proposed antenna possesses controllable triband characteristics and good omnidirectional radiation patterns which make it suitable for WLAN and WiMAX communication applications. 


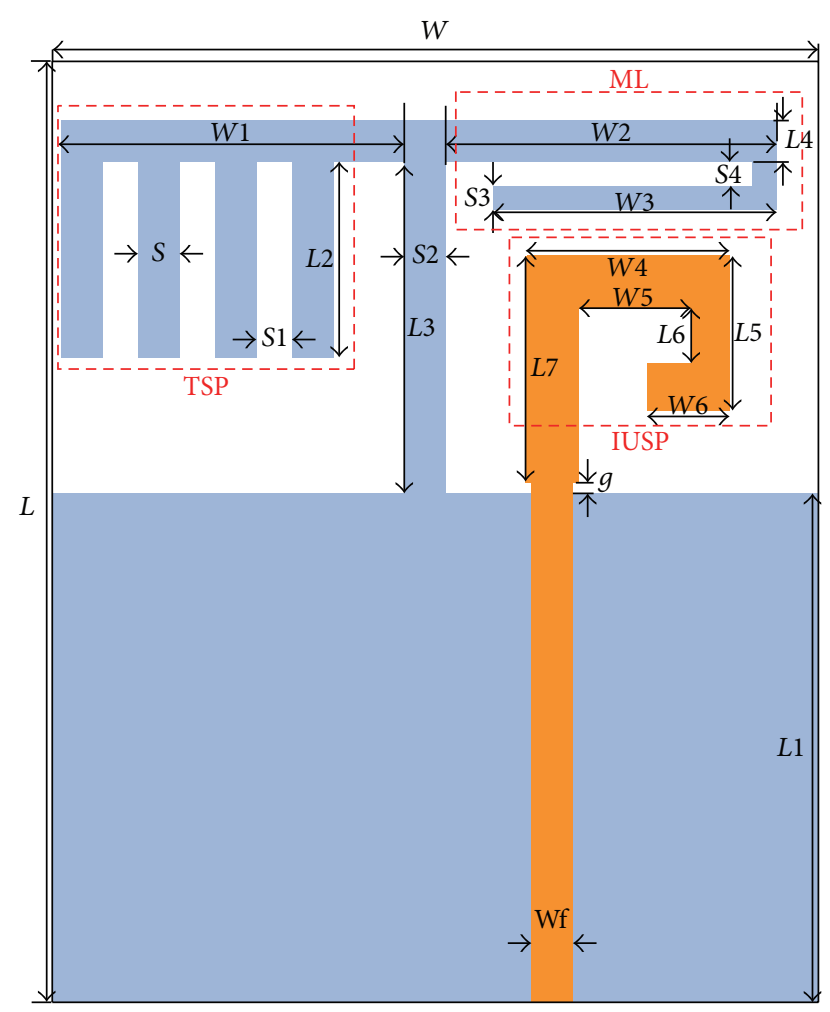

FIGURE 1: Configuration of the proposed triband antenna.

\section{Antenna Design}

Figure 1 depicts the proposed triband monopole antenna, which is fabricated on a FR4 substrate with a relative permittivity of 4.4 , a loss tangent of 0.002 , and a thickness of $0.8 \mathrm{~mm}$. The proposed antenna consists of a TSP, a ML, an IUSP, and a 50-Ohm microstrip-fed structure together with a partial ground plane. The triple bands are achieved by using TSP, ML, and IUSP. The 50-Ohm microstrip-fed structure is comprised of a feed signal strip line with a width of Wf $=1.4 \mathrm{~mm}$ and a partial ground plane. In this design, the TSP and ML are connected with the partial ground plane and are printed at the bottom of the FR4 substrate, while the IUSP is connected with microstrip feed signal strip line and is deigned on top of the FR4 substrate. The ML is used to generate a resonance frequency at $2.4 \mathrm{GHz}$ for lower WLAN band communication application. The TSP is designed to produce a resonance frequency at $3.5 \mathrm{GHz}$ to meet the WiMAX communication requirements, while the higher WLAN bands are obtained by using the IUSP, which aims to give a resonance at $5.5 \mathrm{GHz}$ to cover a wide bandwidth of $5.15-5.825 \mathrm{GHz}$. The center resonance frequencies are tunable by adjusting the dimensions of the TSP, ML, and IUSP to make them suitable for WLAN and WiMAX communication applications. The proposed antenna has been investigated and optimized by the HFSS. The optimized parameters of the antenna are listed as follows: $L=30 \mathrm{~mm}, W=20 \mathrm{~mm}, L 1=20 \mathrm{~mm}, L 2=4.2 \mathrm{~mm}$, $L 3=6.85 \mathrm{~mm}, L 4=1 \mathrm{~mm}, L 5=4.3 \mathrm{~mm}, L 6=1.6 \mathrm{~mm}$, $L 7=5.1 \mathrm{~mm}, W 1=8.5 \mathrm{~mm}, W 2=9 \mathrm{~mm}, W 3=6.8 \mathrm{~mm}$, $W 4=5 \mathrm{~mm}, W 5=2.35 \mathrm{~mm}, W 6=1.8 \mathrm{~mm}, S=1 \mathrm{~mm}$,

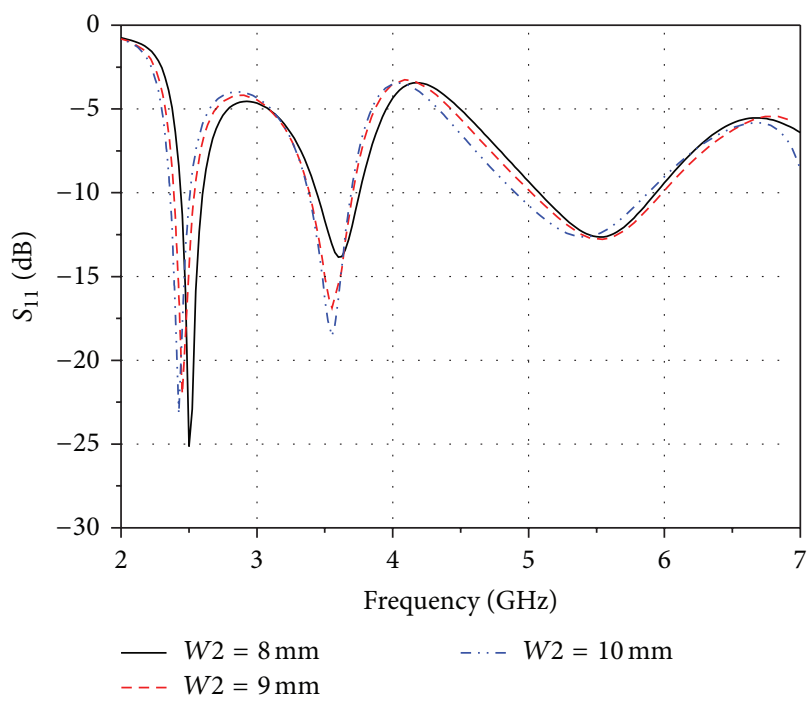

FIGURE 2: Effects of the parameter $W 2$ on the return loss.

$S 1=1 \mathrm{~mm}, S 2=1 \mathrm{~mm}, S 3=0.65 \mathrm{~mm}, S 4=0.4 \mathrm{~mm}$, and $g=0.2 \mathrm{~mm}$.

\section{Results and Discussion}

In order to fully understand the proposed triband antenna, the key parameters $L 2, W 2$, and $W 6$ are selected to investigate their effects on the impedance bandwidth. The effects of $W 2$ on the impedance bandwidth of the proposed antenna are shown in Figure 2. It is observed from the figure that the center frequency of the lower WLAN band at $2.4 \mathrm{GHz}$ shifts from $2.5 \mathrm{GHz}$ to $2.42 \mathrm{GHz}$, which can be tuned within a wide frequency range. In this case, the other two resonance frequencies are slightly changed. This is because the increased $W 2$ increases the total length of the ML and hence extends the resonance length which makes the $2.4 \mathrm{GHz}$ WLAN band move to the low frequency. Moreover, the ML is connected to the partial ground plane, which may affect the current distribution on the partial ground plane, which, in turn, slightly affects resonance characteristic of the TSP. Thus, the WiMAX band at $3.5 \mathrm{GHz}$ has a slight fluctuation.

Figure 3 depicts the parameter effects on the impedance bandwidth with varying $L 2$. It can be seen from Figure 3 that the resonance frequency at $3.5 \mathrm{GHz}$ moves to the low frequency with an increase of $L 2$ ranging from $3.7 \mathrm{~mm}$ to $4.7 \mathrm{~mm}$. Additionally, the $2.4 \mathrm{GHz}$ WLAN band also slightly moves to the low frequency, which is due to the fact that the TSP might affect the ML via the common partial ground plane. The increased $L 2$ not only extends the resonance length of the toothbrush-shaped patch but also changes the current distribution on the partial ground plane. Thus, we can conclude that TSP mainly determines the resonance frequency of $3.5 \mathrm{GHz}$ WiMAX band.

Figure 4 illustrates the performance of the parameter W6. It is observed that the upper WLAN band at $5.5 \mathrm{GHz}$ moves to the low frequency with an increase of $W 6$. As $W 6$ increases from $1.8 \mathrm{~mm}$ to $2.8 \mathrm{~mm}$, the center frequency of 


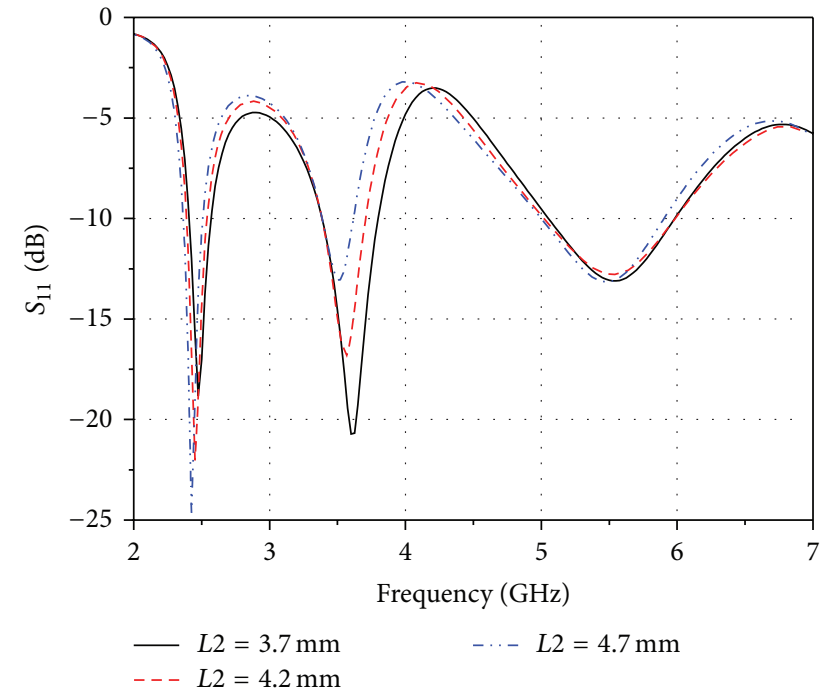

FIGURE 3: Effects of the parameter $L 2$ on the return loss.

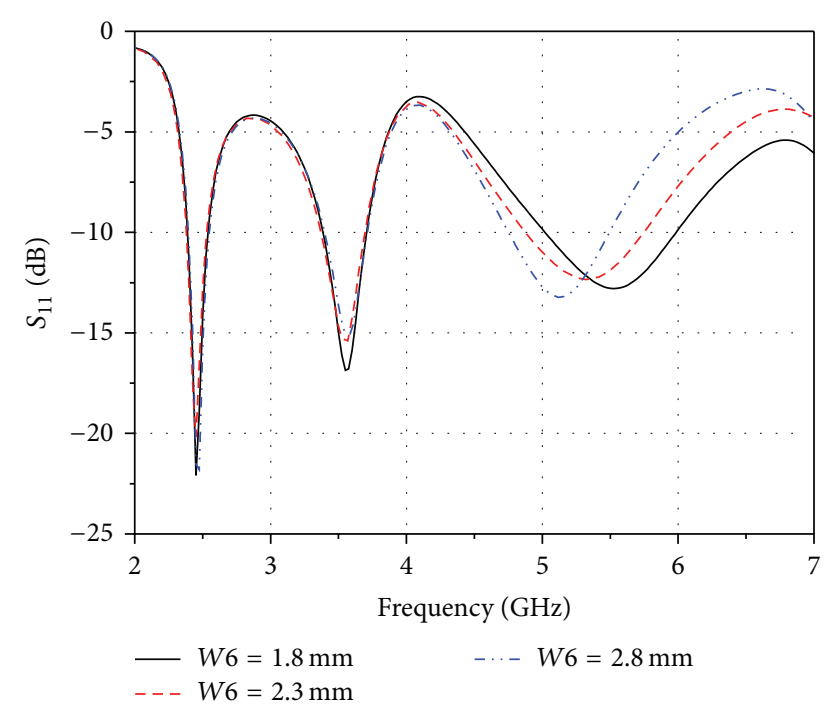

FIGURE 4: Effects of the parameter W6 on the return loss.

the upper WLAN band moves from $5.55 \mathrm{GHz}$ to $5.15 \mathrm{GHz}$. This is because the increased W6 prolongs the total length of IUSP and hence increases the current path on the IUSP. Therefore, the center resonance frequency shifts to the low frequency. In addition, the impedance bandwidth of the highest resonance frequency becomes narrower with the increment of $W 6$. When $W 6$ is equal to $1.8 \mathrm{~mm}$, the upper WLAN band has a bandwidth of $1 \mathrm{GHz}$, which can cover the entire 5.15-5.825 GHz WLAN band.

In order to verify the performance of the proposed triband antenna, the designed antenna has been optimized, manufactured, and measured. The phototype of the fabricated antenna is shown in Figure 5. The measured $S 11$ of the proposed triband antenna, as shown in Figure 6, is obtained by using Agilent N5224A vector network analyzer. It can
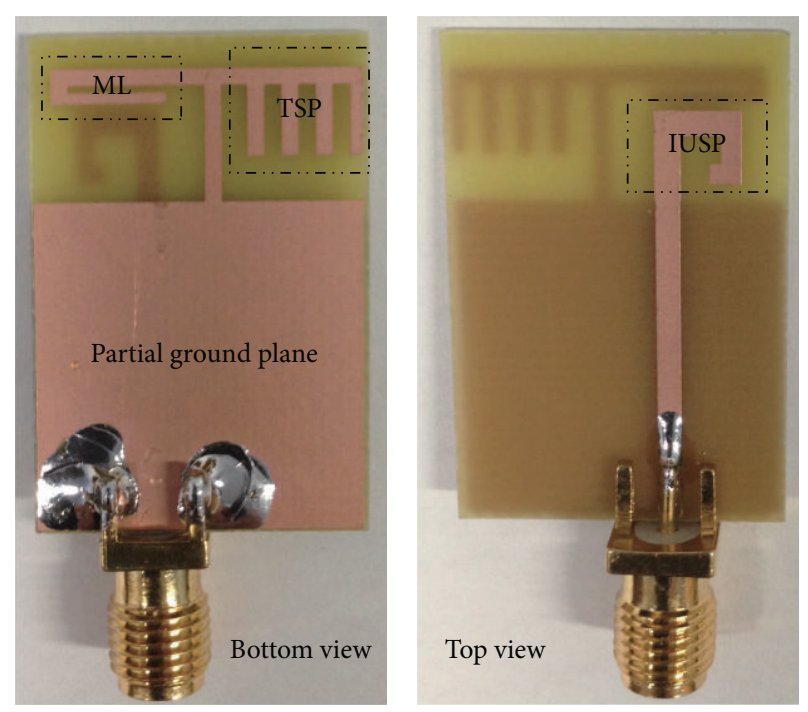

Figure 5: Fabricated antenna.

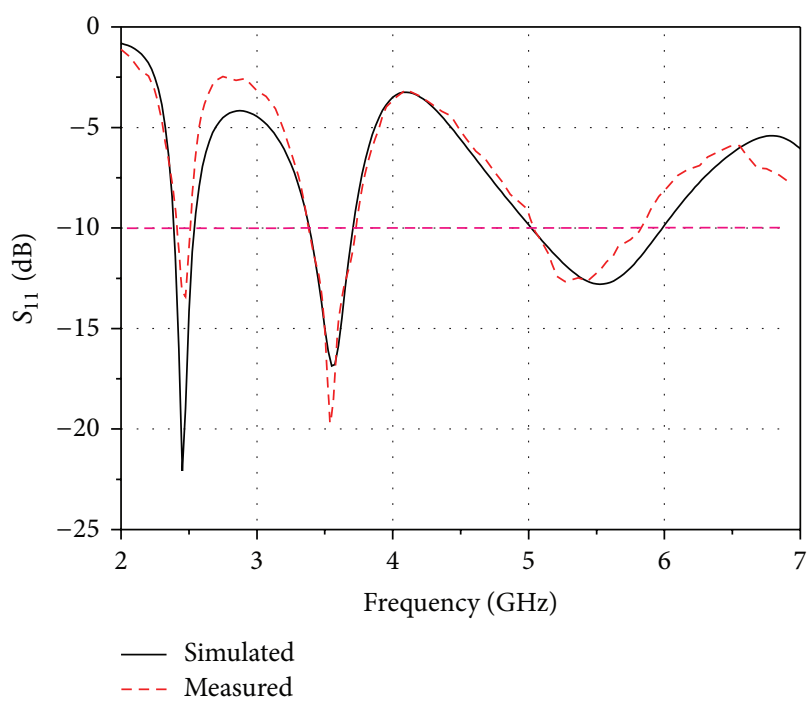

FIGURE 6: Measured S11 of the proposed tri-band antenna.

be seen that the proposed antenna has three resonance frequencies at $2.4 \mathrm{GHz}, 3.5 \mathrm{GHz}$, and $5.5 \mathrm{GHz}$, which can cover the lower WLAN and WiMAX and the upper WLAN bands for $S 11<-10 \mathrm{~dB}$. The bandwidths of the proposed antenna at the desired bands are $140 \mathrm{MHz}, 310 \mathrm{MHz}$, and $840 \mathrm{MHz}$, respectively. On the other hand, the measured $S 11$ agrees well with the simulated one, which helps to validate the effectiveness of the HFSS simulation. However, there are some deficiencies between the measured $S 11$ and the simulated one, which may be caused by the fabrication tolerance and manual welding inaccuracies. The radiation patterns at $2.45 \mathrm{GHz}, 3.5 \mathrm{GHz}$, and $5.5 \mathrm{GHz}$ of the proposed triband antenna are obtained in an anechoic chamber, as shown in Figure 7. We can see that the proposed triband antenna can provide nearly omnidirectional radiation patterns in the $H$-plane and a figure-of-eight radiation pattern in 


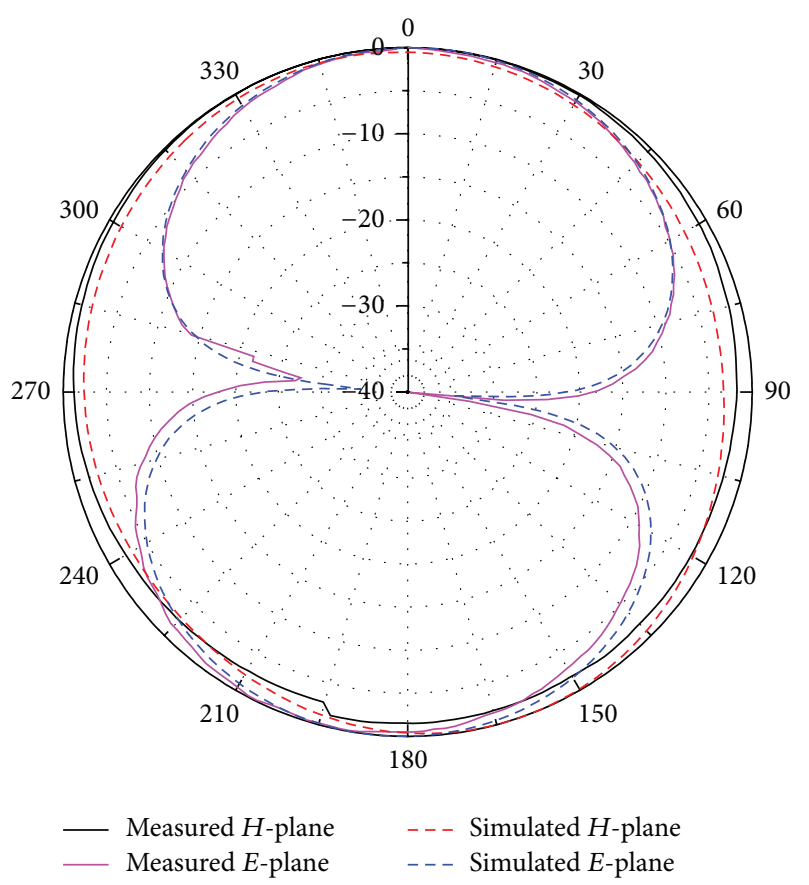

(a) $2.45 \mathrm{GHz}$

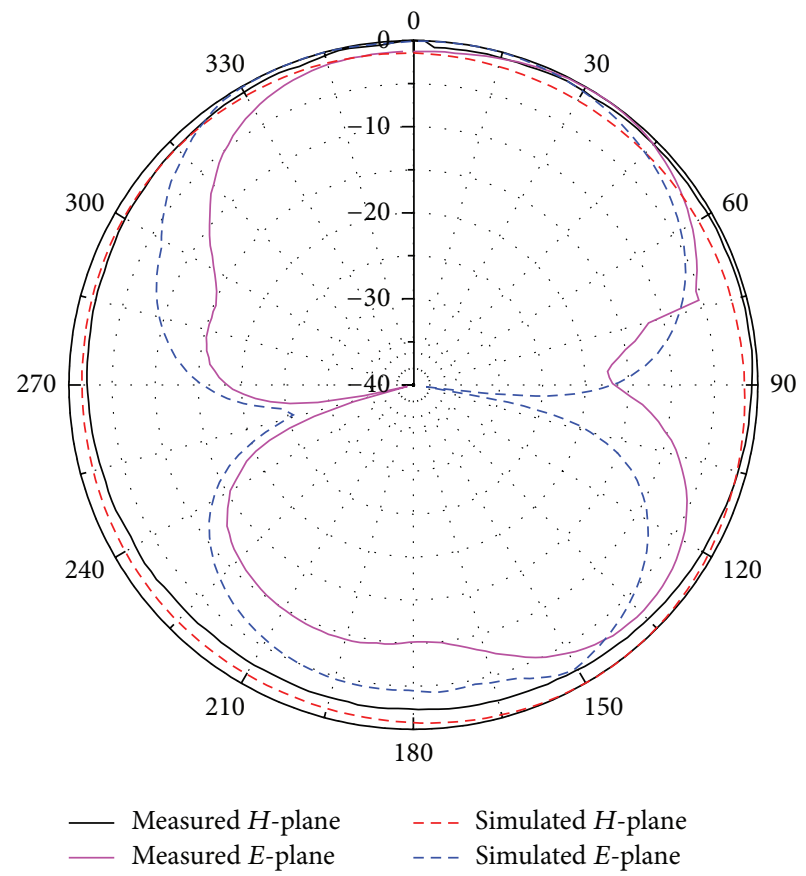

(b) $3.5 \mathrm{GHz}$

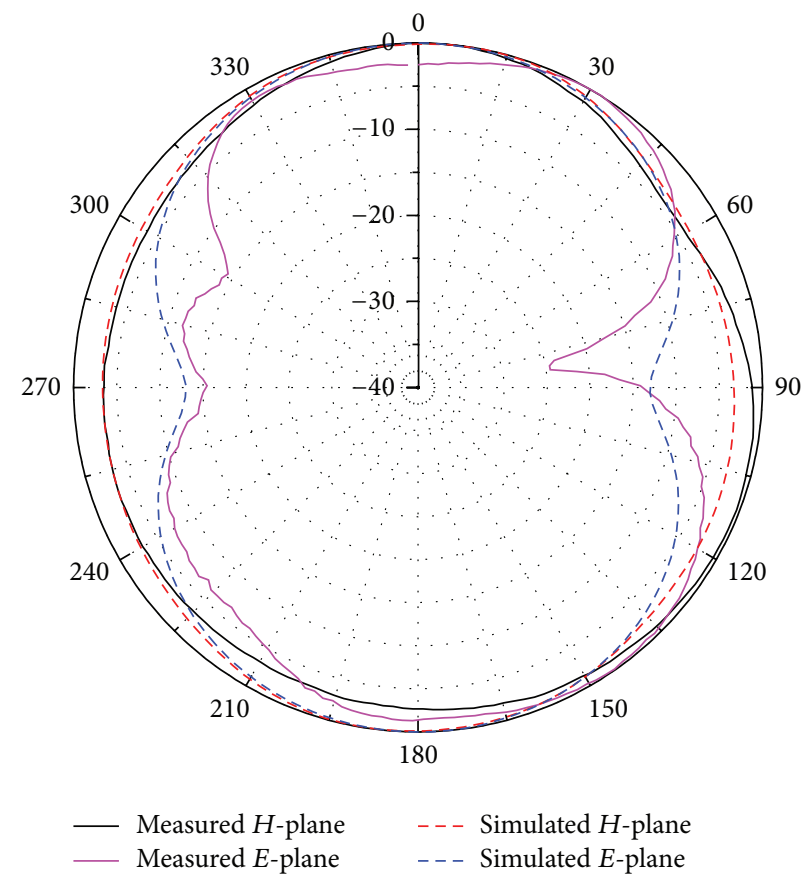

(c) $5.5 \mathrm{GHz}$

FIGURE 7: Radiation patterns of the proposed tri-band antenna.

the E-plane. The gains are obtained by comparing the proposed antenna with a standard horn antenna in an anechoic chamber. The peak gains at the $2.45 \mathrm{GHz}, 3.5 \mathrm{GHz}$, and $5.5 \mathrm{GHz}$ are $1.3 \mathrm{dBi}, 2.2 \mathrm{dBi}$, and $3.0 \mathrm{dBi}$, respectively.

Table 1 compares the proposed antenna with previously proposed multiband antennas with respect to the size and the operating bands. We note that a few previously proposed antennas can provide triple bands to cover the 2.4/3.5/5.2/5.5/5.8 GHz. Although some of the early reported antennas have smaller sizes than our proposed antenna [1, $6,11]$, they cannot cover all the above mentioned operating bands. As for our proposed antenna with an excellent triple band characteristic, it has a smaller size than those of the previously proposed triple antennas in $[4,9]$. 
TABLE 1: Comparisons of several existing multiband antennas.

\begin{tabular}{lcc}
\hline References & Dimensions & Operating bands \\
\hline$[1]$ & $17 \times 12$ & $2.4 / 5.8 \mathrm{GHz}$ \\
{$[3]$} & $22 \times 29$ & $2.4 / 3.5 / 5.2 / 5.8 \mathrm{GHz}$ \\
{$[6]$} & $11 \times 6.7$ & $5.8 \mathrm{GHz}$ \\
{$[9]$} & $38 \times 25$ & $2.4 / 3.5 / 5.2 / 5.5 / 5.8 \mathrm{GHz}$ \\
{$[11]$} & $17 \times 12$ & $3.5 / 5.8 \mathrm{GHz}$ \\
Proposed antenna & $30 \times 20$ & $2.4 / 3.5 / 5.2 / 5.5 / 5.8 \mathrm{GHz}$ \\
{$[2]$} & $40 \times 20$ & $2.4 / 5.2 / 5.8 \mathrm{GHz}$ \\
{$[4]$} & $37 \times 18$ & $2.4 / 3.5 / 5.2 / 5.5 / 5.8 \mathrm{GHz}$ \\
{$[7]$} & $30 \times 50$ & $2.4 / 5.2 / 5.8 \mathrm{GHz}$ \\
{$[8]$} & $38 \times 30$ & $2.4 / 5.2 / 5.8 \mathrm{GHz}$ \\
{$[10]$} & $40 \times 20$ & $2.4 / 5.2 / 5.8 \mathrm{GHz}$ \\
{$[12]$} & $20 \times 35$ & $2.4 / 5.5 / 5.8 \mathrm{GHz}$ \\
\hline
\end{tabular}

\section{Conclusion}

A compact microstrip-fed triband monopole antenna has been proposed and its performance has been investigated both numerically and experimentally. The toothbrushshaped patch, meander line, and inverted U-shaped patch have been employed to generate the desired $2.4 \mathrm{GHz}$, 3.5 GHz, and $5.5 \mathrm{GHz}$ bands for WLAN and WiMAX communication applications. The proposed antenna has a small size and can provide triple wide operating bands. The numerical and experimental results demonstrated that the designed triband antenna can provide three tunable operating bands and good omnidirectional radiation patterns, which makes it suitable for integrating into portable devices.

\section{Conflict of Interests}

The authors declare that there is no conflict of interests regarding the publication of this paper.

\section{Acknowledgments}

This work was partially supported by a grant from Pre-Research Fund of the 12th Five-Year Plan (no. 4010403020102) and Fundamental Research Funds for the Central Universities (nos. HEUCFD1433, HEUCF1508).

\section{References}

[1] Y. Li, W. Li, and Q. Ye, "A compact asymmetric coplanar strip-fed dual-band antenna for 2.4/5.8 GHz wlan applications," Microwave and Optical Technology Letters, vol. 55, no. 9, pp. 2066-2070, 2013.

[2] X. L. Sun, L. Liu, S. W. Cheung, and T. I. Yuk, "Dual-band antenna with compact radiator for 2.4/5.2/5.8 GHz WLAN applications," IEEE Transactions on Antennas and Propagation, vol. 60, no. 12, pp. 5924-5931, 2012.

[3] A. Mehdipour, A.-R. Sebak, C. W. Trueman, and T. A. Denidni, "Compact multiband planar antenna for 2.4/3.5/5.2/5.8-GHz wireless applications," IEEE Antennas and Wireless Propagation Letters, vol. 11, pp. 144-147, 2012.
[4] H. Zhai, Z. Ma, Y. Han, and C. Liang, "A compact printed antenna for triple-band WLAN/WiMAX applications," IEEE Antennas and Wireless Propagation Letters, vol. 12, pp. 65-68, 2013.

[5] X. D. Yang, Y. S. Li, and C. Y. Liu, "A toothbrush-shaped patch antenna for millimeter-wave communication," Journal of Electromagnetic Waves and Applications, vol. 23, no. 1-2, pp. 3137, 2009.

[6] C.-P. Lai, S.-C. Chiu, and S.-Y. Chen, "Miniaturization of CPWfed slot antennas using reactive terminations and truncated bilateral ground plane," IEEE Antennas and Wireless Propagation Letters, vol. 11, pp. 1072-1075, 2012.

[7] C.-Y. Huang and E.-Z. Yu, "A slot-monopole antenna for dual-band WLAN applications," IEEE Antennas and Wireless Propagation Letters, vol. 10, pp. 500-502, 2011.

[8] K. G. Thomas and M. Sreenivasan, "Compact triple band antenna for WLAN/WiMAX applications," Electronics Letters, vol. 45, no. 16, pp. 811-813, 2009.

[9] J. Pei, A.-G. Wang, S. Gao, and W. Leng, "Miniaturized triple-band antenna with a defected ground plane for WLAN/WiMAX applications," IEEE Antennas and Wireless Propagation Letters, vol. 10, pp. 298-301, 2011.

[10] S. Verma and P. Kumar, "Compact triple-band antenna for WiMAX and WLAN applications," Electronics Letters, vol. 50, no. 7, pp. 484-486, 2014.

[11] A. Khaleghi, "Dual band meander line antenna for wireless LAN communication," IEEE Transactions on Antennas and Propagation, vol. 55, no. 3, pp. 1004-1009, 2007.

[12] Y. Li, W. Li, and R. Mittra, "A compact ACS-FED dualband meandered monopole antenna for WLAN and WiMAX applications," Microwave and Optical Technology Letters, vol. 55, no. 10, pp. 2370-2373, 2013.

[13] Y. S. Li, X. D. Yang, Y. Bai, and T. Jiang, "Dual-band antenna handles WLAN/WiMAX," Microwaves \& RF, vol. 50, no. 1, pp. 80-88, 2011. 

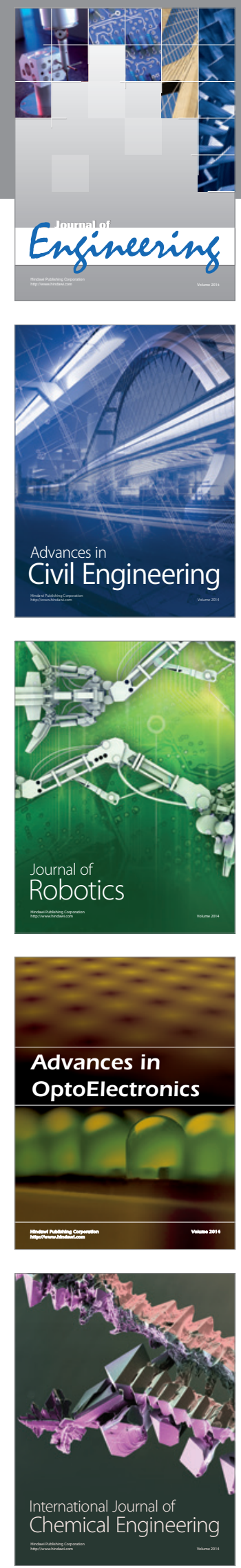

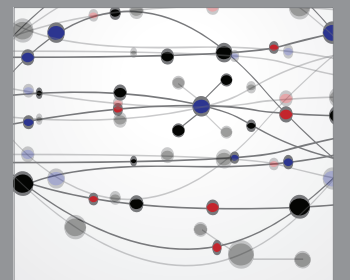

The Scientific World Journal
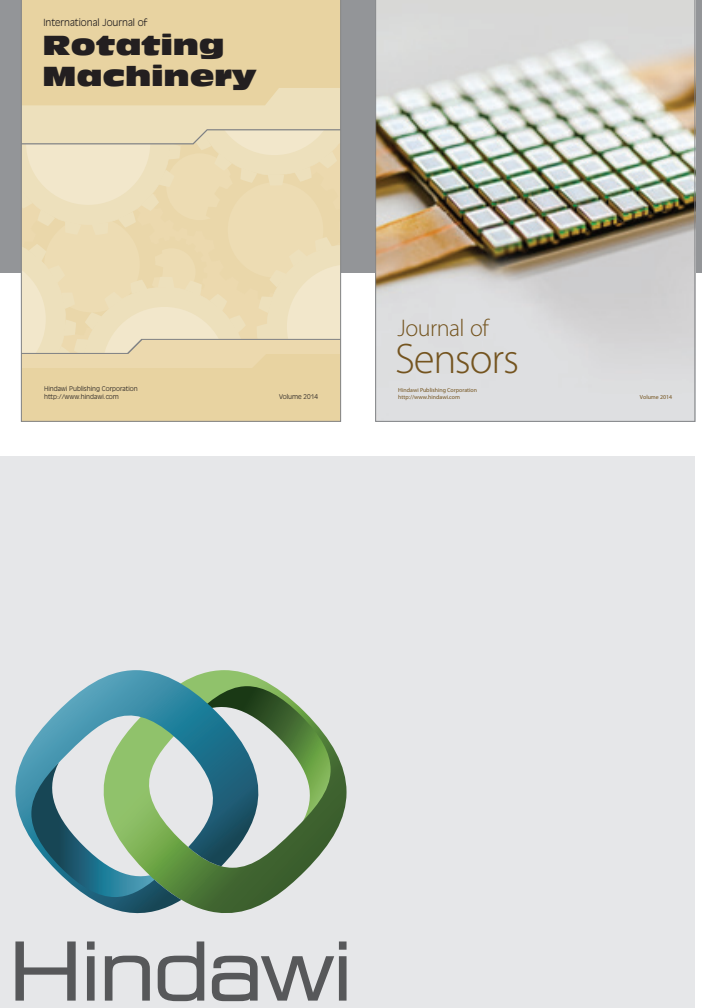

Submit your manuscripts at http://www.hindawi.com
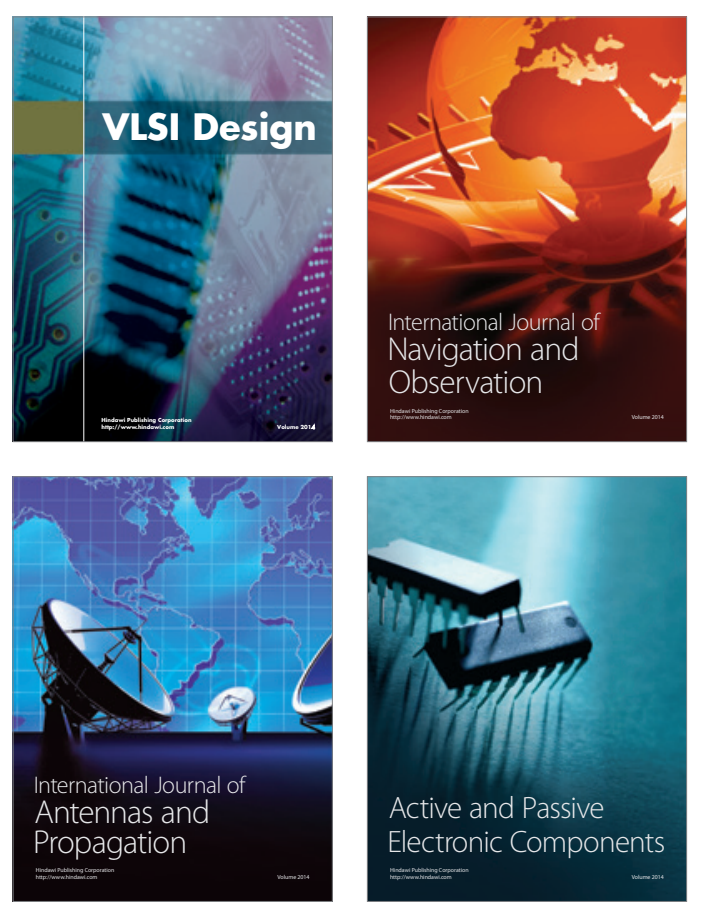
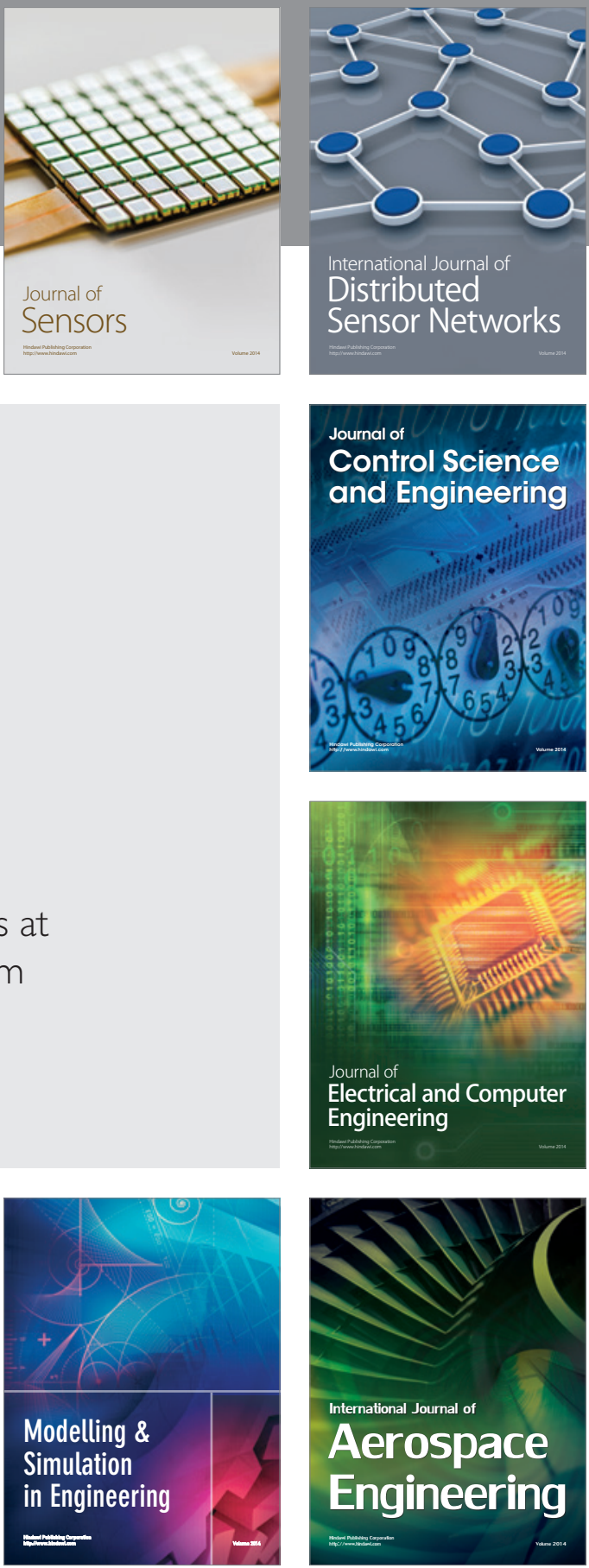

Journal of

Control Science

and Engineering
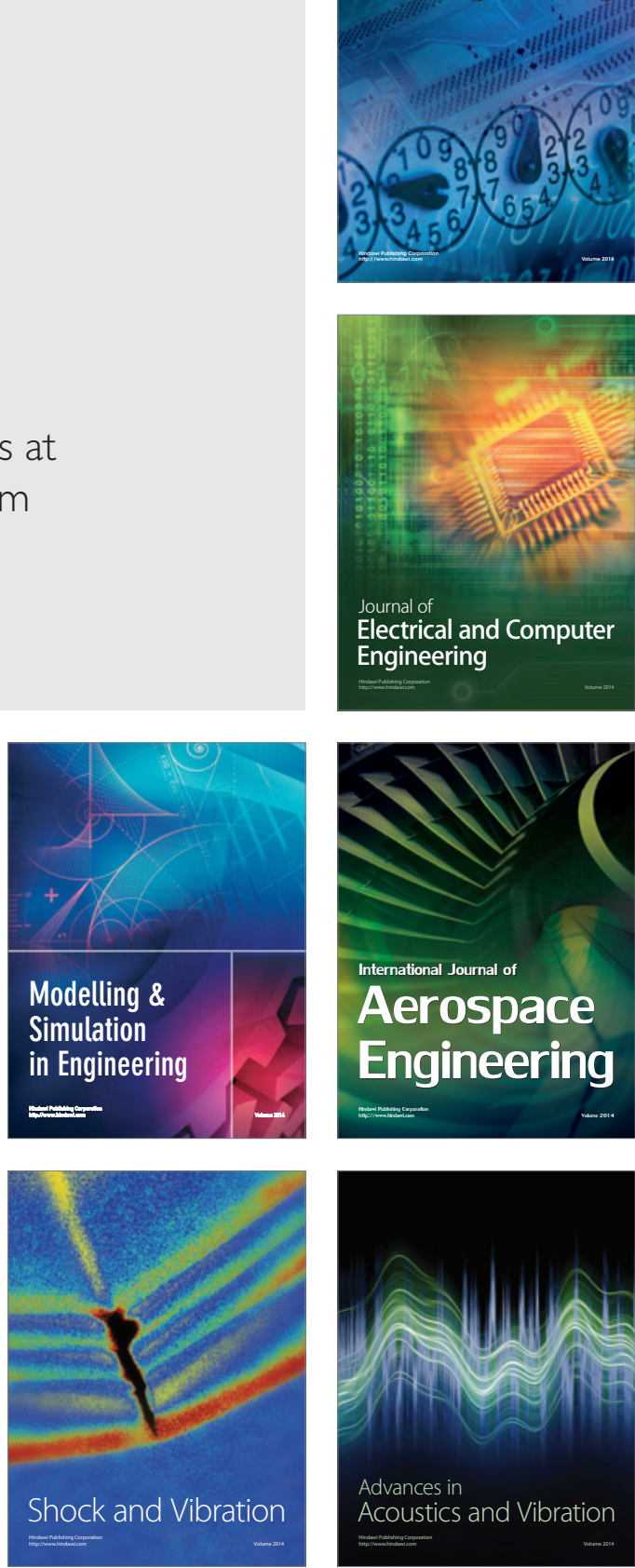